\title{
3D DATA PROCESSING TOWARD MAINTENANCE AND CONSERVATION. THE INTEGRATED DIGITAL DOCUMENTATION OF CASA DE VIDRO
}

\author{
M. Balzani ${ }^{1}$, F. Maietti ${ }^{1 *}$, L. Rossato ${ }^{1}$ \\ ${ }^{1}$ University of Ferrara, Department of Architecture, Ferrara, Italy, (bzm, federica.maietti, luca.rossato)@unife.it
}

\section{Commission II}

KEY WORDS: 3D Integrated Survey, Documentation, Point cloud processing and analysis, Modernist Heritage, Brazil

\begin{abstract}
:
During the last decade, 3D integrated surveys and BIM modelling procedures have greatly improved the overall knowledge on some Brazilian Modernist buildings. In this framework, the Casa de Vidro 3D survey carried out by DIAPReM centre at Ferrara University, beside the important outputs, analysis and researches achieved from the point cloud database processing, was also useful to test several awareness increasing activities in cooperation with local stakeholders.

The first digital documentation test of the Casa de Vidro allowed verifying the feasibility of a full survey on the building towards the restoration and possible placement of new architectures into the garden as an archive-museum of the Lina Bo and P.M. Bardi Foundation. Later, full 3D integrated survey and diagnostic analysis were carried out to achieve the total digital documentation of the house sponsored by the Keeping it Modern initiative of Getty Foundation (Los Angeles). Following its characteristics, the survey had to take into consideration the different architectural features, up to the relationship of architecture and nature.

These 3D documentation activities and the point cloud processing allowed several analysis in a multidisciplinary framework.
\end{abstract}

\section{INTRODUCTION}

In order to face the challenge of the preservation of modern buildings, public bodies and professionals should be able to pick the right tools for the documentation, monitoring and yearly maintenance of these architectures. According to this aim, the 3D surveying methodology developed over the years by the DIAPReM Centre (Development of Integrated Automatic Procedures for Restoration of Monuments) has been addressed also to point cloud processes and analysis aimed at diagnosis and planning of restoration project in Brazil. These activities, since 2003 has highlighted the need of conscious flexibility and a smart vision by deep knowledge of buildings, also in terms of digital data. These data should be used as a base for students and academics (not only in Brazil) for further analyses on both built and unbuilt architectures or more specific research on the Modernist architecture even from afar. The 3D integrated survey is of great importance in this process of knowledge toward a real scheduled maintenance program. The cooperation with the scanners manufacturers in Brazil has shown how it could be possible to use expensive tools even in medium budget projects. This could help to improve the spreading out of new technologies in heritage field in Brazil and the creation of a laboratory net able to develop autonomously local methodologies for the preservation of Modernist buildings.

This paper summarizes the research activities carried out through an integrated digital documentation procedure on the Casa de Vidro in São Paulo, Brazil, by the renowned architect Lina Bo Bardi. The aim of the data capturing and processing was to support and enhance the knowledge of this masterpiece of Modernist architecture fostering conservation and maintenance actions.

After a short introduction describing the main features of the House, an overview about related works in the field of preservation of Modern architectures is presented, focusing on the state of the art regarding the application of integrated technologies for modern buildings preservation. A detailed description of the applied methodology of digital documentation of Casa de Vidro is followed by the description of the data processing and analysis. The 3D documentation activities and the point cloud processing, integrated with diagnostic assessments, were performed within a multidisciplinary framework.

Heritage management is a strong interdisciplinary filed involving many actors in the complex process that, starting from the documentation, leads to the preservation, enhancement and sustainable exploitation of assets. Holistic and critical researches and an inclusive interdisciplinary approach are more and more needed. This approach was essential to develop a conservation management plan of Casa de Vidro based on the 3D survey, digital documentation and diagnostic analysis.

\subsection{Casa de Vidro}

Casa de Vidro by the Italian architect Lina Bo Bardi is a result of the Twentieth Century global exchange of architectural ideas and forms over the centuries by the geographical movements and migrations of architects and engineers. Brilliant young architects such as Affonso Eduardo Reidy (from France to Brazil), Clorindo Testa (from Italy to Argentina), Gregory Warchavchic (from Italy to Brazil) and many others brought abroad the European modern construction methods and patterns the which were replicated in a diversity of cultural, geographical and climatic contexts. Pattern of formal transfer were not always straightforward, with inventive combination of local influences. Among these Lina Bo and her husband Pietro Maria Bardi were responsible for relevant interventions in the Brazilian cultural scene (Acayaba, 2011). Pietro lead MASP (São Paulo Art Museum) and invested in forming the musicological sector in the country. Architect Lina acted on different sectors such as design, education, cinema, fashion and the environmental consciousness. The Casa de Vidro, the first building to be completed by Lina Bo Bardi (1951) became an icon of Modernist architecture and represents an everlasting innovative thinking and lifestyle of the couple: simple, engaged, filled with diversity, possibilities and beauty (De Oliveira, 2006). The house has an important affinity with the work of the masters such as Le Corbusier (ville Sovoye) even if it appears more linked to the nature if compared with the buildings designed by the French-Suisse architect. It is frequently inserted in history of architecture books as one of the most interesting examples of glass houses along with Glass House by 
Philip Johnson (1946-1949) and Farnsworth House by Mies Van Der Rohe, built in the same period (Figure 1). Slim metal columns support the front of the house, which is defined by the horizontal planes of floor slabs: nothing blocks the view, the house interprets the relationship of architecture and nature as Lina applies to a building's contact with the ground.

An essential granite staircase with a thin metal structure that leads to the door highlights the main access to the house. The entrance is a prelude to the huge open space lounge, paved with a mosaic floor, from where the landscape is framed by the big windows and the curtains in a vibrating connection with the trees of the garden (Brown, 2000) designed by Lina to slowly grow up and protect the house from the strong sun light of Sao Paulo. The house is thus seen as a transparent box floating in the midst of nature (Cavalcanti, 2003).

Beside the big glass module of dining hall the rest of the house has dormitory and service areas, which occupy the three later modules and configure the massive and opaque part of the house. The dorms are adjacent to the living room and the service area forms the last module to the north. Connecting these two tracks is the kitchen, which along with another open patio, wider than that of the living room, conform the central strip of this massive portion of the residence. The patio is once again an essential element for the comfort of the house, allowing ventilation of all the bedrooms. On the first floor, there are also the machine areas and the garage. The Lina's studio was built later in 1986 using wood and clay tiles. It is located in the middle of the tropical garden, nowadays completely surrounded by the lush vegetation.

\section{RELATED WORKS}

Modern buildings are, for their innovative concepts, shapes and materials are very often badly maintained or even demolished. "The explosion of building technology starting in the late nineteenth century led to innovative building forms and construction materials that now pose new conservation challenges. This theme explored the approaches needed to advance the field in relation to environmental, technical, and physical conservation" (Normandin et al., 1996).

\subsection{The preservation of Modern Architectures}

During the last decades local, national, and international organizations have been created in order to conserve modern heritage: among these Docomomo International, the Modern Heritage Committee of the Association for Preservation Technology (APT), the ICOMOS International Scientific Committee on Twentieth-Century Heritage, modern Asian Architecture Network. This wide range of institutions / organizations demonstrates an interest toward the recent built architecture of 20th century. In this framework the work developed by Docomomo International since its establishment in 1988, has been hugely influential in creating a network of academics and professionals willing to preserve the Modern Cultural Heritage. The institution is still enhancing the practice of modern architecture preservation and simultaneously aims to conserve the legacy of modern architects.

In the 1990s professional organizations such as APT and government heritage agencies in Europe and North America started to organize conferences and workshops and issue publications on technical issues and all these materials were the basis for a continuous development of an international practice supported also by ICOMOS International Scientific Committee on Twentieth-Century Heritage. Since 2000s, many other organizations have also been working in a variety of ways to improve the quality of knowledge in this area of conservation.
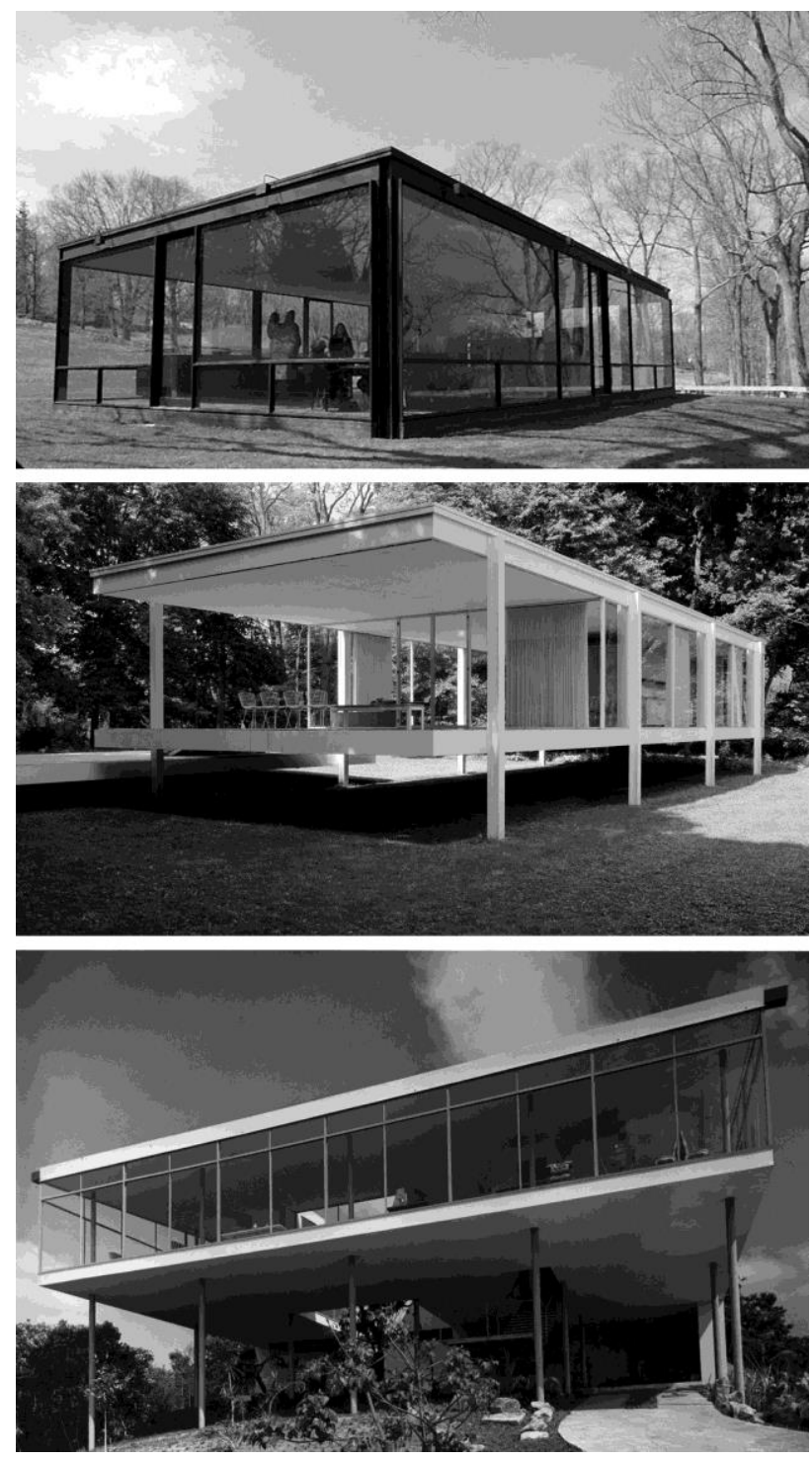

Figure 1: From above, Glass House by Philip Johnson (19461949), Farnsworth House by Mies van der Rohe (1945-1951) and Casa de Vidro by Lina Bo Bardi (1950-1951)

Nevertheless, even if many efforts have led to a better preservation of some 20-century buildings, according to Susan Macdonald "Considering twenty-five years of practice and all that has been achieved, it would be easy to surmise that modern heritage is well loved, cared for, and conserved. However, many important twentieth-century places remain unprotected. There is still little research addressing common technical problems impeding the repair of these buildings. With the termination of the Conservation of Modern Architecture course - a partnership of various Finnish institutions and ICCROM - there is no dedicated training on the subject at an international level, and there are only isolated opportunities at national levels" (Macdonald, 2001).

Heritage professionals do not always have enough scientific data on the nature and behaviour of these materials and systems to develop the necessary protocols for conservation treatment (Ioannides et. a., 2016).

To address these challenges, the Getty Foundation in Los Angeles, USA, developed Keeping It Modern, a grant initiative that continues our deep commitment to the conservation of historic buildings. Keeping It Modern supports grant projects of 
outstanding architectural significance that promise to advance conservation practices.

\subsection{Application of integrated technologies for modern buildings preservation}

As stated by Yehuda Kalay, Thomas Kvan, Janice Affleck in New Heritage: New Media and Cultural Heritage, "the complement of traditional methods to cultural heritage management has been augmented with the introduction of digital or new media. [...] Digital media can be utilized for much more than re-creation or re-presentation of physical entities. It has the capacity to become a tool to capture both the tangible and intangible essence of cultural heritage and the society that created or used the sites". (Kalay et al., 2008).

The application of such techniques may bring a wide and common evolution, influencing preservation and enhancement policies of cultural heritage currently adopted in Brazil with the optimization of management strategies and improvement of knowledge on modern heritage. Moreover, if metric accuracy and photo realism are also taken into consideration, the $3 \mathrm{D}$ models are of course a powerful tool in particular for archaeological and architectural applications (Manferdini \& Remondino, 2010)

Within this framework the work carried out by Wilson Florio (Florio et al., 2004) and Ana Tagliari (Tagliari, 2012) in Brazil in recent times was able to focus the attention on both built and unbuilt residential architectures through digital tools such as 3D modelling.

The modern heritage is slowly becoming a tourism attraction and despite challenges and lost opportunities the tourism flows would need to be managed and very well calibrate to preserve the right balance between conservation and enhancement. As identified by J.T. Dallen (Dallen, 2009) one of the most frequent threat to cultural heritage sites (in global south countries) is the lack of management plans. In order to achieve an effective management system of cultural heritage buildings several digital tools can be useful if properly adapted to modernism features and materials. Among these tools the three-dimensional survey has always been proved to be essential to represent areas that would be otherwise impossible to analyses, for example elevations surrounded by trees, and to find plan matches essential to understand the architectural "philosophy" on which the designers has based the realization of a project.

In the representative phase there is a motivational value, which makes the survey-representation a real project itself, with significant critical implications aimed at the determination not only of geometric precision but, especially in architecture, of visualization and conceptual representation of reality. The 3D survey can be strong tool for future conservation projects of modernist buildings and it will preserve the memory of these extraordinary architectures (Georgopoulos, 2017). Furthermore, the 3D laser scanner survey is consistent with the digitalization process that is being carried out by many Foundation Archives, one of the priority in order to create drawings archive for researchers and academics willing to explore the modernism research field.

There is a strong need of multinational projects able to improve the capacity of local professionals in modern heritage preservation and management field. Learning-by-doing activities able to take advantage of cooperation between different institutions play a key role in heritage preservation in former developing countries (Kappagoda, 2002). For instance, the cooperation project between the Department of Architecture at University of Ferrara and FUSP foundation at USP (Sao Paulo, Brazil) through digital representation and advanced analysis has stressed the importance of having a point cloud model of the external concrete surfaces of modernism building. This was the basis to investigate in detail the formal characteristics, geometric textures and surface features (Balzani et al., 2017).

\section{DEVELOPED METHODOLOGY}

The first test survey of Casa de Vidro has been developed in 2016 within the cooperation framework between the São Paulo University (especially with Instituto de Arquitetura e Urbanismo - IAU São Carlos - and Prof. Renato Anelli), the Instituto Lina Bo and P.M. Bardi (São Paulo) and the DIAPReM research center.

These first quick campaigns of laser scanner surveys allowed to verifying the feasibility of a full survey on the building (Bianchini et. al., 2018) towards the restoration and possible insertion of new architectures into the garden as an archivemuseum of the Foundation (Figure 2).

Along this phase the advanced decay of the garden's retaining walls designed by Lina required a particularly targeted survey, which will allow the preliminary assessment of the state of conservation of the structures.

Due to the needs for a preventive, scheduled maintenance plan based on specialized technical surveys to avoid an uncertain future of emergency interventions and ad hoc spot repairs, Casa de Vidro was granted under the Getty Foundation Keeping it Modern Program, and so in 2017, a full 3D integrated survey (Ramos and Remondino, 2015) - both laser and topographic - and diagnostic analysis was planned and carried out by the same partners to achieve the total digital documentation of the house. Following its characteristics, the survey had to take into consideration the different architectural features, up to the relationship of architecture and nature (Pritchard, 2017).

Due to overall complexity of the architecture, its environment, and the external features (vegetation, materials, structural features and conservative conditions) the geometric, morphometric and diagnostics documentation of Casa de Vidro was performed by integrating different procedures:

- 3D laser scanner survey by time-of-flight technology (Laser Scanner Leica P20 and P30) to obtain a high-accuracy 3D metric model;

- Topographic survey (Leica Total Station TS11 1" R 1000), for scan-registration procedure and the definition of the local reference system;

- On-site analysis and photographic documentation of the building, surroundings and overall state of conservation as the base for diagnostic assessment for defining the state of conservation of the surfaces.

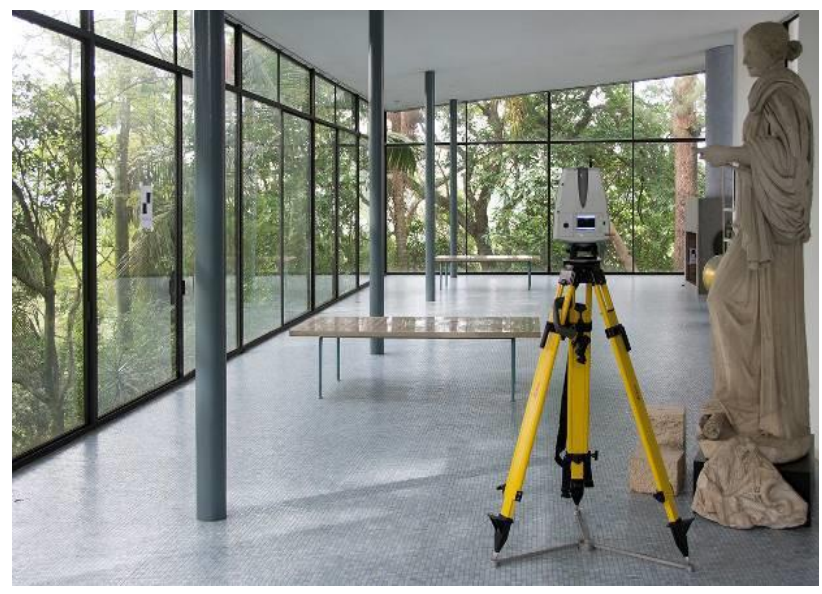

Figure 2: Interior view of Casa de Vidro during the data capturing procedure 


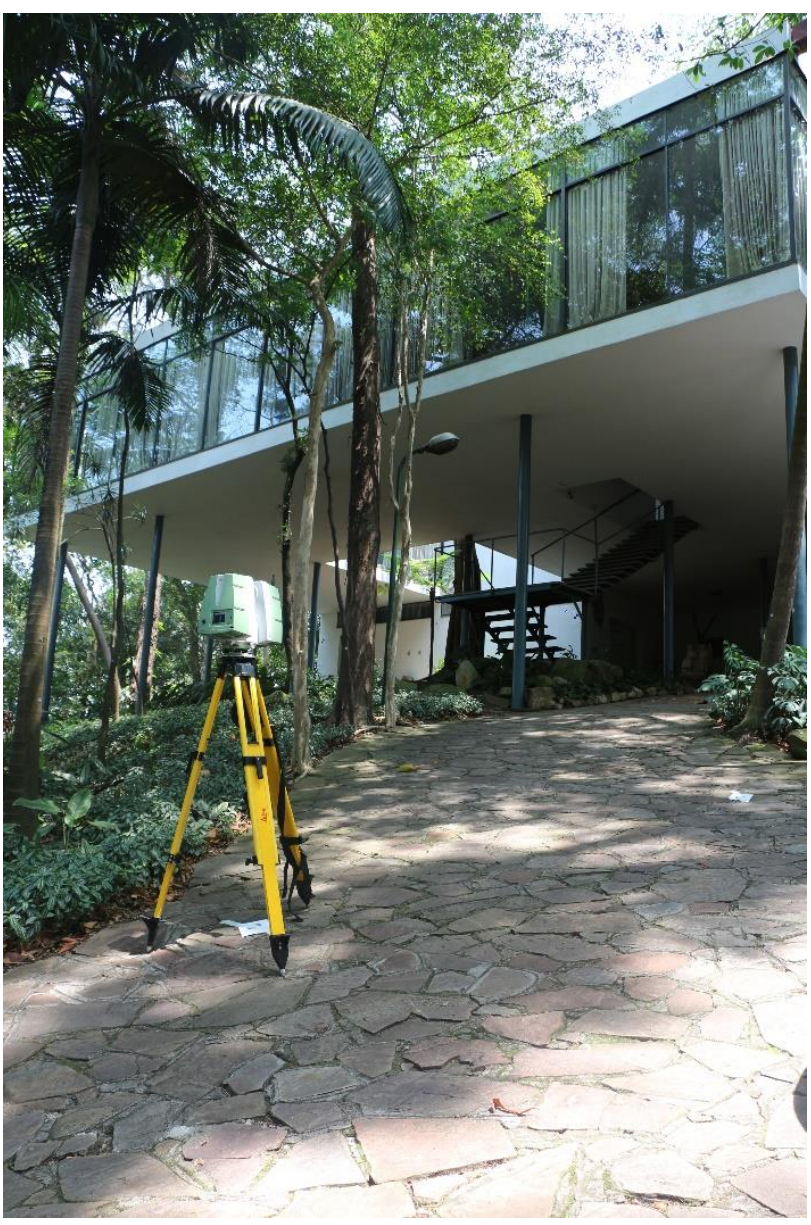

Figure 3: External view of Casa de Vidro during the data capturing procedure

\subsection{Digital documentation}

As already mentioned, despite similarities of Casa de Vidro with architectures by Mies Van der Rohe and Le Corbusier, it appears less metaphysical and more linked to the nature. Following its characteristics, the survey had to take into consideration the different architectural features: from the slim metal columns supporting the front of the house, which is defined by the horizontal planes of floor slabs, to the relationship of architecture and nature (Figure 3).

The second 3D survey allowed also the study of the structure of the house, designed to disappear with its 17 centimetres diameter of pipe columns and the light staircase hanged in the air giving a mobile and provisional feeling about its fragile design, a solution also used later for the MASP project (De Oliveira, 2014).

The survey carried out in 16 working days was based on a multiple methodological integration in order to obtain a set of data to be critically investigated in depth:

1) 3D scanner survey aimed at generating a point cloud model;

2) detailed topographic survey of the homology points;

3) high-resolution photographic survey aimed at an overall and detailed documentation of the house's state of conservation.

The scanner stations points were selected so the individual scans could gather the most metric information and the highest number of homology points (target) allowing, subsequently, a better alignment during registration.

The three-dimensional survey was performed using a Leica P30 scanner (speed: $1 \mathrm{mln}$ points / $\mathrm{s}$, accuracy on single measurement:
$3 \mathrm{~mm} / 50 \mathrm{~m}$, linear error $<1 \mathrm{~mm}$, maximum acquisition distance: $120 \mathrm{~m})$. On the external portions no particular difficulties have been detected in data acquisition; however, great attention was paid to the garden paths (sometimes less accessible due to the inclination of the ground). A detailed topographic survey (based on targets acquisition) composed of open polygonal with control points for the targets was also completed (carried out by Leica total station TS11 R1000). The survey campaign has been documented by a detailed photographic survey.

\begin{tabular}{|l|c|}
\hline General info & \\
\hline Mission start & 23 January 2017 \\
\hline Mission end & 11 February 2017 \\
\hline Days of work & 14 working days \\
\hline Hours of work & 2 \\
\hline Technicians & \\
\hline & \\
\hline Survey data & $\begin{array}{c}\text { Leica P30 and Leica total } \\
\text { station TS11 R1000 }\end{array}$ \\
\hline Equipment & 135 hours \\
\hline Time of data capturing & 197 \\
\hline Number of scan stations & 296 \\
\hline Number of targets & 8.430 .499 .869 \\
\hline $\begin{array}{l}\text { Number of points } \\
\text { (coordinates) }\end{array}$ & \\
\hline
\end{tabular}

Table 1: Survey data and information

In total, 135 hours of data capturing were performed on site, 197 scans were carried out, and 296 targets were used; the total measured coordinates were $8,430,499,869$.

The alignment phase allowed the recording and the combination of the data: the resulting 3D model is made up of more than 8 million points (xyz coordinates) which refer to a system of local coordinates (Table 1). In addition, the individual points are accompanied by a specific intensity value.

The overall cloud can be queried at any time both in the source software (Leica Cyclone 9.2.0) and in many other software compatible with the original imp format. The registration phase followed the on-site metric survey of the house and it took more than one month to be completed.

The analysis phase dealt with the topic of visual and analytical querying of the data. The process placed therefore a preventive constraint on the obligatory determination of useful and necessary reference plans in order to extract data in the form of horizontal and vertical sections for understanding morphology relations (Pavlidis et. al., 2007).

The relations that link the wall thicknesses to the huge window frames according to the xy cutting planes (horizontal sections) and the relations that bind the patio and the slim columns on the $\mathrm{xz}-\mathrm{yz}$ cutting planes (longitudinal and transversal vertical sections) were accurately determined.

\subsection{Data processing and analysis}

After the data acquisition steps, data processing (Weinmann, 2016) and analysis of the intensity values obtained by 3D scanning were performed as a support for mapping the state of conservation (Gonçalves et. al., 2017).

These 3D documentation activities and the point cloud processing allowed several analysis in a multidisciplinary framework:

- the study of the structure of the house, designed to "disappear" into the surrounding environment; 


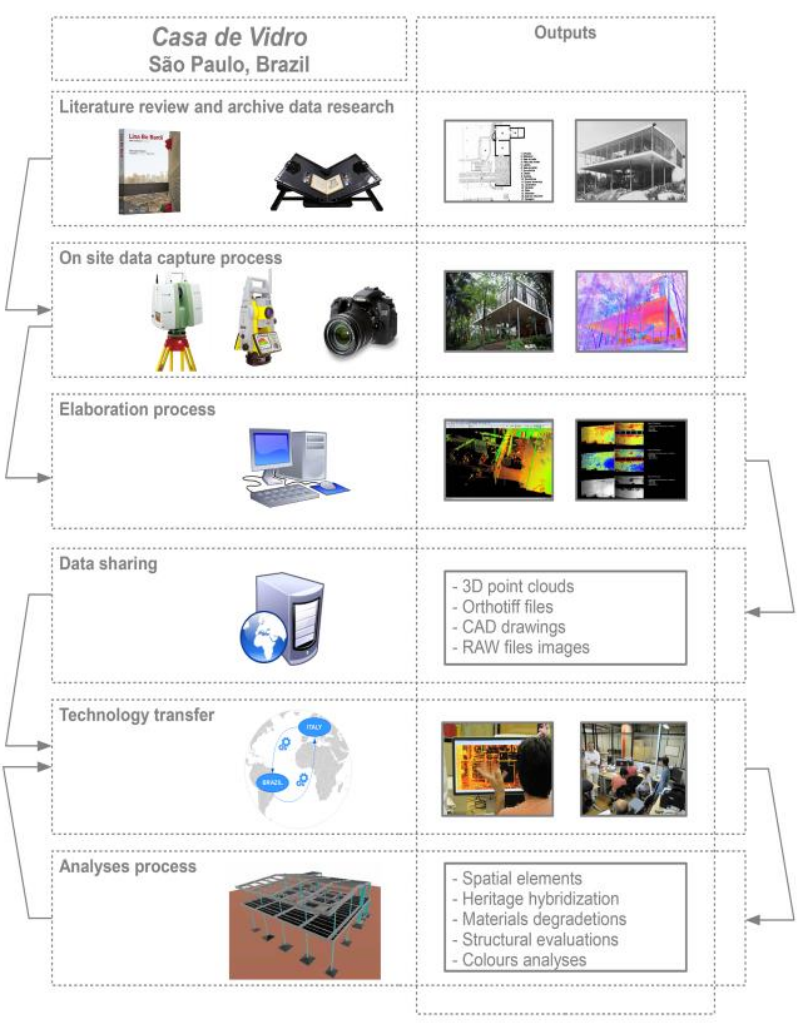

Figure 4: The integrated data acquisition methodology applied during the digital documentation of Casa de Vidro, and the main outputs achieved

- the setting up of a scanning methodology: the house is nowadays surrounded by greenery from all sides and this was one of the major difficulties during the survey.

The winding paths in the gardens provided numerous routes for a walk but many trees were more than an obstacle for the laser during the operations (Figure 5);

- the analysis of the relations among architecture and landscape: the project is designed to fit the topography of the site by exploiting the full potential in terms of isolation and immersion into the nature and, at the same time, let the vegetation enters and appropriates architecture, integrating with it. Thanks to several cross-sections extracted from the database this relation is finally precisely determined;

- point cloud processing and analysis aimed at the assessment of the state of conservation mainly regarding the effects/damages of vegetation on the building.

While dealing with the database, it became even more clear the strong unity between the outside and the inside, the natural and the artificial that is expressed through the integration between the house and the hill where it is located, one of the driving forces of the design. It was not just a matter of creating a beautiful setting around the dwelling; by looking at the garden she planned, the data showed how she wanted to make the house part of the landscape.

The project is designed to fit the topography of the site by exploiting the full potential in terms of isolation and immersion into the nature and, at the same time, let the vegetation enters and appropriates architecture, integrating it. Thanks to several cross sections extracted from the database this relation is finally precisely determined.

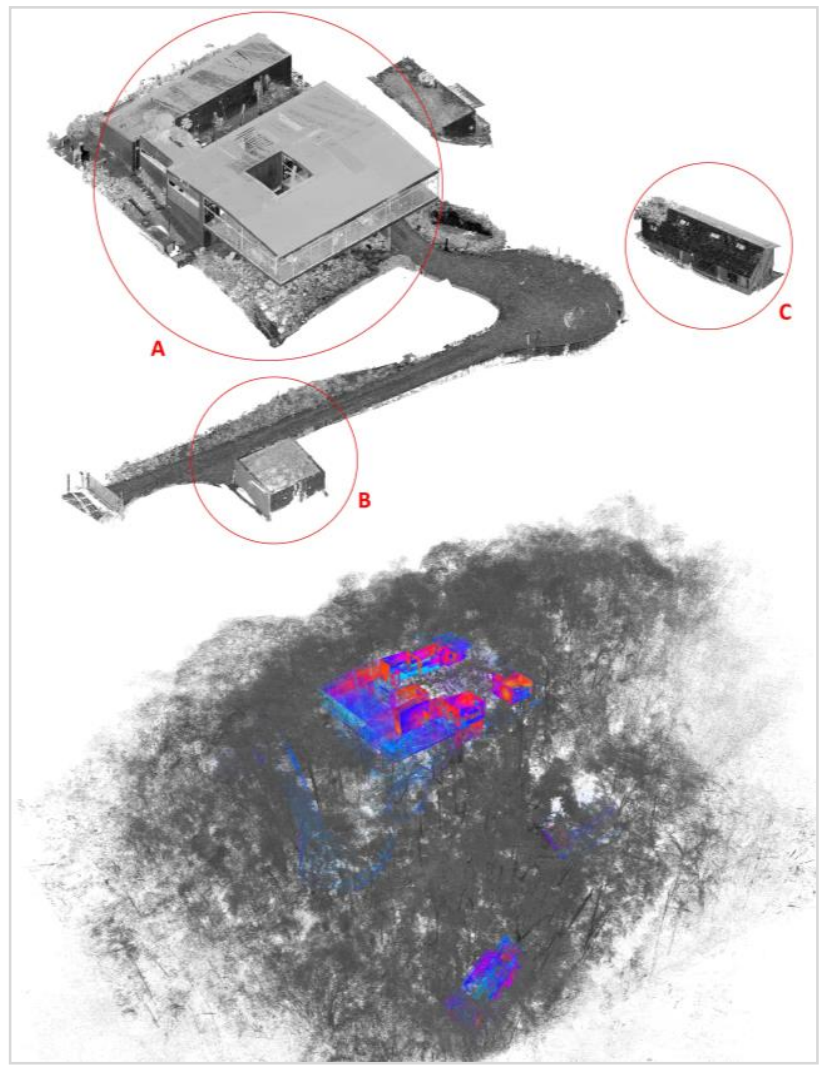

Figure 5: Casa de Vidro and the relationship with the landscape: on the top, image extraction from 3D database of the house, (A) the garage (B), and the Lina Bo Bardi's office (C)

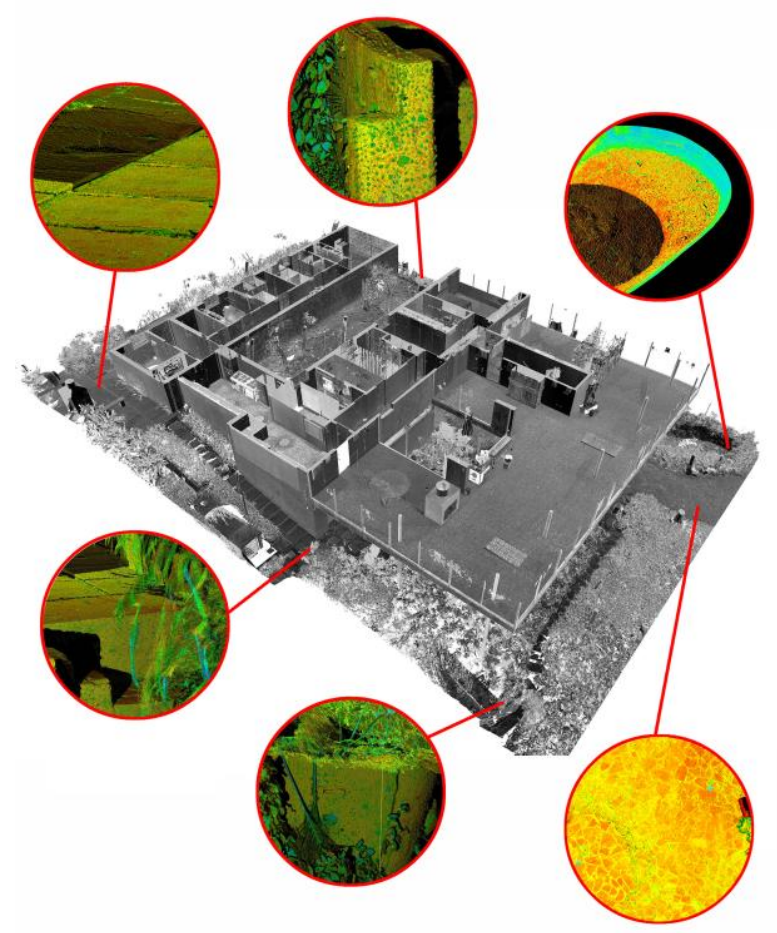

Figure 6: Identification by point cloud analyses of concrete cracks on external walls due to vegetation pressure 


\subsection{Diagnostic assessment by processing the intensity value}

The house is currently facing some problems regarding the deterioration of materials (Cacciotti et. al., 2015). One of the main degradation issues is the besetting of vegetation, which is growing on external walls and on horizontal surfaces due to the local climate, making some cracks visible due to the vegetation pressure (Figure 6). The digital survey campaign, including the external areas and the garden, has been integrated by a diagnostic survey to map the state of conservation and the main degradation issues (Kioussi et. al., 2012).

After a first general inspection of the whole building, a macroscopic analysis of deteriorations has been implemented on the basis of the nomenclature of the UNI Normal 1/88 recommendation (Figure 7). The result of the visual analysis will be related to the surface specifications surveyed by means of the 3D laser scanning and particularly through reflectance data (Balzani and Maietti, 2008).
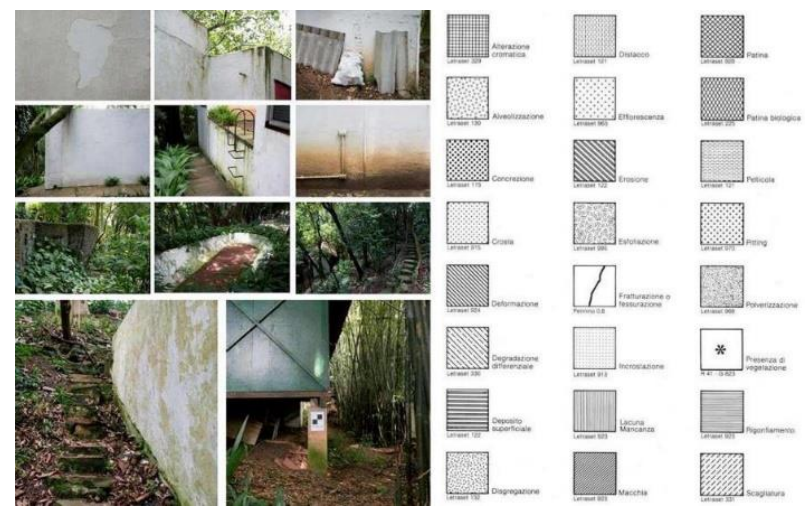

Figure 7: Main degradations affecting the surfaces of part of the house identified during the on-site diagnostic survey

The vegetation, deliberately integral part of the architecture, determines some consequences, while the presence of moisture damages the building's state of conservation, especially along the external wall of the lower floor.

Besides vegetation, the main degradations surveyed on external surfaces are:

- biological patina and biological crust;

- chromatic alteration;

- surface deposit;

- lacuna;

- deformation and detachment.

The main deteriorations on interior surfaces concern:

- lacuna and deformation of the plaster;

- moisture stains and biological crusts.

The knowledge of the main deterioration issues as an additional "level" of the integrated survey allowed a precise mapping of the detected damages to contribute to conservation actions. In addition to the macroscopic on-site visual recognition of the main deteriorations affecting the house, the digital geometric model (point cloud) was the basis for processing the intensity values acquired by laser scanning (Table 2). This procedure was an essential integration to the macroscopic investigations in order to manage additional information related to surface characteristics displayable on the point cloud. This data processing has been applied to some representative areas of external surfaces of the house (Figure 8). Chosen samples were selected on the basis of the main significant surface specifications (considering both materials/architectural features and state of conservation), surfaces where an in-depth analysis was interesting and significant for the overall assessment. The set of intensity values' analysis on the point cloud was performed considering different parameters (environmental conditions, scanner technical characteristics, angles of different scan position during the survey, etc.).
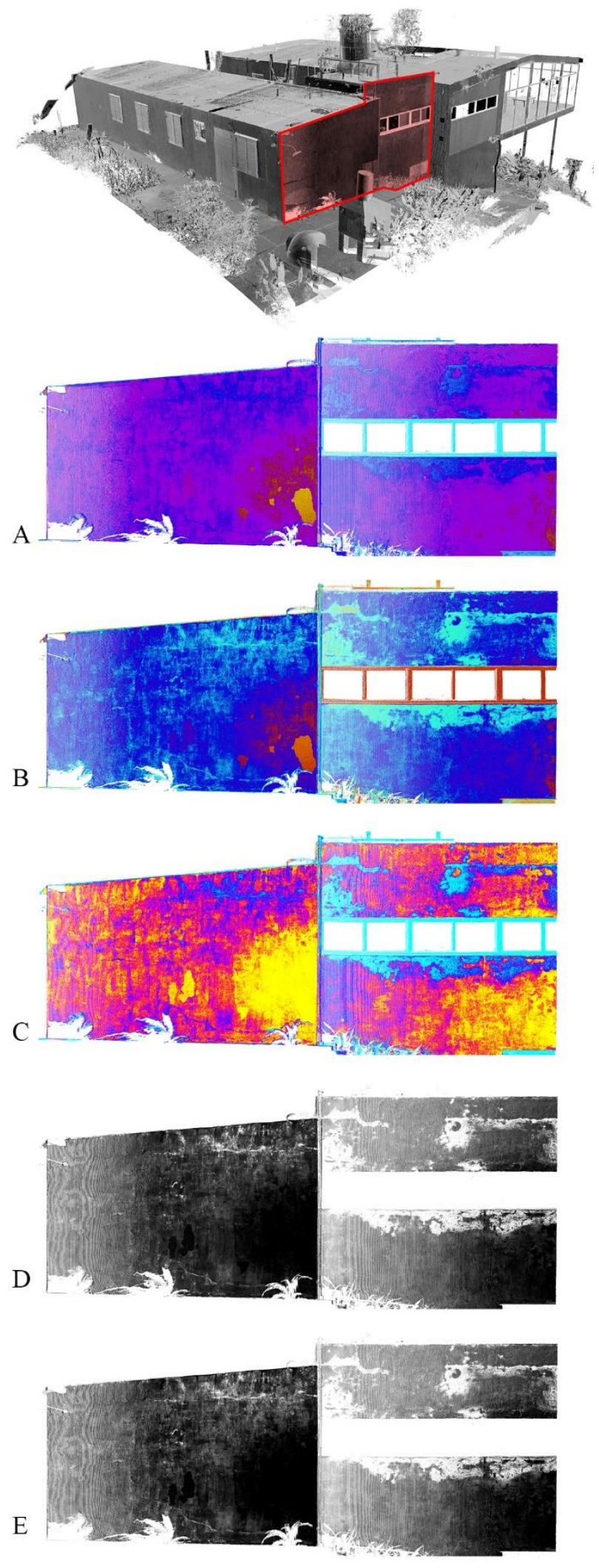

Figure 8: Elaboration of intensity values of the point cloud of Casa de Vidro, processed by several parameters and aimed at visualizing and analysing surface specifications (see Table 2) 


\begin{tabular}{|c|l|l|l|l|}
\hline \multicolumn{6}{|c|}{ Intensity values } \\
\hline Image & Method & Min & Max & Gamma \\
& & & & \\
\hline A & multi hue & 0.0013 & 0.9994 & 0,45 \\
\hline B & multi hue & 0.15 & 0.95 & 0,45 \\
\hline C & multi hue & 0.20 & 0.50 & 0,45 \\
\hline D & grayscale & 0.25 & 0.60 & 0,45 \\
\hline E & grayscale & 0.24 & 0.90 & 0,65 \\
\hline
\end{tabular}

Table 2: Intensity values data tested during the post-processing in colours from scanner and greyscale visualization

\section{CONCLUSIONS}

The applied methodology has been developed in order to support maintenance and conservation procedures. This approach is focused on an effective data usage for decision making related to conservation and preventive interventions and for supporting site management and sustainable exploitation by integrating condition assessment survey based on predictive analysis (diagnostic, conservative, morphometric) and non-destructive procedures (Kioussi et. al., 2015).

Beside the massive amount of 3D data and related drawings, one of the main outputs of the project was also aimed at technology transfer to allow the staff of IAU (Institute of Architecture and Urbanism of Sao Carlos) getting familiar with the integrated digital approach (Balzani et. al., 2018). In order to achieve an effective methodology transfer on activities of diagnosis of the facades deterioration (towards a future complete analysis of all the surfaces of the house), a 30 hours seminar has took place at the IAU USP headquarter in São Carlos. During the seminar the staff of the DIAPReM research centre has been teaching the methodology that helped later the staff to complete the diagnostic procedures independently. The topics of the seminar has been discussed and chosen in cooperation with IAU USP staff and they were related on one hand to the representation by database inquiring of façades and plans of the whole complex and on the other hand to macroscopic analysis of the degradation of the surfaces and their classification and nomenclature. The achieved objective of this seminar has been to train the University staff to continue and complete the characterization of the state of conservation on the whole building.

The whole research study demonstrated the effectiveness of international and multi-disciplinary cooperation for the preservation of modern building through integrated technologies. The project was split by the coordinator in 4 tasks aiming at the complete documentation and analyses of the house designed by Lina. In this framework were carried out (by a team of more than 20 people both with academic and professional background) historic documentation and archive research activities, landscape studies on the tropical garden, digital documentation and material condition evaluation, structural analyses via BIM modelling and eventually the conservation plan.

The grant provided by The Getty Foundation allowed the international team of conservation architects, landscape conservation specialists, cultural heritage experts, and civil and structural engineers to develop a conservation management plan for the property on the basis of the 3D survey of the site and diagnostic analysis based on the digital documentation.

\section{ACKNOWLEDGEMENTS}

This research was totally financed by The Getty Foundation (Los Angels, USA) through the Keeping it Modern initiative. The
Getty grant allowed different 3D analysis developed in cooperation with the international staff involved into the project. This study was only possible due to the helpful support on-site of Istituto Lina Bo e P.M. Bardi (São Paulo, Brazil). The effective cooperation with the colleagues of Instituto de Arquitetura e Urbanismo (São Carlos, Brazil) has been crucial for the development of the analyses and the technology transfer. In particular the authors of this contribution would like to express their deepest appreciation to Prof. Renato Anelli and Prof. Ana Lúcia Cerávolo (IAU, USP), whose contribution in stimulating suggestions and encouragement during the on-site data capturing and the final phases of data sharing was immensely supportive.

\section{Credits}

Project: DIAPReM research centre, University of Ferrara, Department of Architecture

Scientific coordinator: Prof. Marcello Balzani

Project coordinators: Arch. Luca Rossato, Arch. Ana Lúcia Cerávolo

Survey coordinator: Arch. Daniele Felice Sasso

Diagnostic survey: Arch. Federica Maietti

Photo survey: Arch. Laura Abbruzzese

Scientific partners: Instituto Lina Bo e P.M. Bardi (São Paulo, Brasile), Instituto de Arquitetura e Urbanismo (São Carlos, Brazil)

Technical support: Leica Geosystem Brazil (Rio de Janeiro, San Carlos, São Paulo)

In cooperation with: Consorzio Futuro in Ricerca

\section{REFERENCES}

Acayaba Milan, M., 2011. Residências em São Paulo: 19471975. Romano Guerra Editores, São Paulo.

Balzani, M. and Maietti, F., 2008. Development of integrated procedures for diagnosis of architectonical surfaces. In: Proceedings of the International Workshop SMW08 In situ monitoring of monumental surfaces, Edifir Edizioni, Firenze, pp. 131-140.

Balzani, M., Maietti, F., Mugayar Kühl, B., 2017. Point cloud analysis for conservation and enhancement of modernist architecture. In: Int. Arch. Photogramm. Remote Sens. Spatial Inf. Sci., XLII-2/W3, pp. 71-77.

Balzani, M., Maietti, F., Rossato, L., 2018. Research activities on Brazilian cultural heritage: a cooperation net in the field of technologies for survey and representation. In: Bertocci S. (Ed.), Programmi multidisciplinary per l'internazionalizzazione della ricerca. Patrimonio culturale, Architettura e Paesaggio. Conference Proceedings of Symposium of representation scientific area for development of multidisciplinary international programs, DIDApress, Firenze, pp. 61-65.

Bianchini, C., Senatore L.J., Catena, L., 2018. Survey 2.0: from theory to practice. In: Rappresentazione/Materiale/Immateriale Drawing as (in)tangible representation. Gangemi Editore, Roma, pp. 329-336

Brown, J., 2000. El Jardín Moderno. Gustavo Gili, Barcelona.

Cacciotti, R., Blasko, M., Valach, J., 2015. A diagnostic ontological model for damages to historical constructions. In: Journal of Cultural Heritage, 16 (1), pp. 40-48.

Cavalcanti, L., 2003. When Brazil was modern: guide to architecture, 1928-1960. Princeton Architectural Press, New York. 
Dallen, J.T., 2009. Cultural Heritage and Tourism in the Developing World: A Regional Perspective. Routledge, New York.

De Oliveira, O., 2014. Lina Bo Bardi, Obra costruida. Editorial Gustavo Gili, São Paulo, 2014.

De Oliveira, O., 2006. Sutis substâncias da arquitetura de Lina Bo Bardi. Romano Guerra/GG, São Paulo/Barcelona.

Florio, W., Gallo, H., Santanna, S.S., Magalhaes, F., 2004. Projeto residencial moderno e contemporâneo: análise gráfica dos princípios de forma, ordem e espaço de exemplares da produção arquitetônica residencial - residências internacionais. Volume II, MackPesquisa, São Paulo.

Georgopoulos, A., 2017. Data Acquisition for the Geometric Documentation of Cultural Heritage. In: Mixed Reality and Gamification for Cultural Heritage. Springer, Cham, pp. 29-74.

Gonçalves, J., Mateus, R., Silvestre, J. D., Vasconcelos, G., 2017. Survey to architects: challenges to inspection and diagnosis in historical residential buildings. In: $3 r d$ International Conference on Preservation, Maintenance and Rehabilitation of Historical Buildings and Structures (REHAB 2017). Green Lines Institute for Sustainable Development, pp. 3-10.

Ioannides, M., Fink, E., Moropoulou, A., Hagedorn-Saupe, M., Fresa, A., Liestøl, G., Rajcic, V., Grussenmeyer, P. (Eds.), 2016. Digital Heritage. Progress in Cultural Heritage: Documentation, Preservation, and Protection, 6th International Conference, EuroMed 2016. Springer, Berlin-Heidelberg.

Kalay, Y., Kvan, T., Affleck, J., 2008. New Heritage: New Media and Cultural Heritage. Routledge, New York.

Kappagoda, A., 2002. Conserving World Cultural Heritage Sites in Developing Countries: Sri Lanka, a Case Study. University of New South Wales press, Kensington.

Kioussi, A., Karoglou, M., Bakolas, A., Moropoulou, A., 2012. Integrated Documentation Protocols Enabling Decision Making in Cultural Heritage Protection. In: Ioannides M., Fritsch D., Leissner J., Davies R., Remondino F., Caffo R. (eds). Progress in Cultural Heritage Preservation. EuroMed 2012. Lecture Notes in Computer Science, vol 7616. Springer, Berlin, Heidelberg, pp. 211-220.

Kioussi, A., Skordaki, N., Karoglou, M., Bakolas, A., Moropoulou, A., 2015. Integrated protocol for non-destructive testing investigation of historic buildings. Sensor Letters, 13(7), pp. 565-572.

Macdonald, S., 2001. Preserving post-war heritage: the care and conservation of mid-twentieth century architecture. Donhead, London.

Manferdini, A.M. and Remondino, F., 2010. Reality-Based 3D Modeling, Segmentation and Web-Based Visualization. In: Ioannides, M., Fellner, D., Georgopoulos, A., Hadjimitsis, D.G. (eds) Digital Heritage. EuroMed 2010. Lecture Notes in Computer Science, vol 6436. Springer, Berlin, Heidelberg.

Normandin, K. and Macdonald, S., 2013. A Colloquium to Advance the Practice of Conserving Modern Heritage. The Getty Conservation Institute, Los Angeles.

Pavlidis, G., Koutsoudis, A., Arnaoutologlou, F., Tsioukas, V., Chamzas, C., 2007. Methods for 3D digitization of cultural heritage. Journal of Cultural Heritage, 8, pp. 93-98.

Pritchard, D., Sperner, J., Hoepner, S., Tenschert, R., 2017. Terrestrial laser scanning for heritage conservation: the Cologne
Cathedral documentation project. ISPRS Annals of Photogrammetry, Remote Sensing \& Spatial Information Sciences, Vol. IV-2/W2, pp. 213-220.

Ramos, M.M. and Remondino, F., 2015. Data fusion in cultural heritage a review. ISPRS-Int. Archives of the Photogrammetry, Remote Sensing and Spatial Information Sciences, 5, W7, pp. 359-363.

Tagliari, A., 2012. Os projetos residenciais não-construídos de Vilanova Artigas em São Paulo. Tese de Doutorado. FAUUSP, São Paulo.

Weinmann, M., 2016. Preliminaries of 3D Point Cloud Processing. In: Reconstruction and Analysis of $3 D$ Scenes. Springer, Cham, pp. 17-38. 